\title{
Tailoring mechanical properties of sol-gel hybrids for bone regeneration through polymer structure
}

\author{
Justin J. Chung', Siwei Li', Molly M. Stevens ${ }^{1,2,3}$, Theoni K. Georgiou', and Julian R. Jones ${ }^{1^{*}}$ \\ ${ }^{1}$ Department of Materials, Imperial College London, SW7 2AZ, London, UK \\ ${ }^{2}$ Institute of Biomedical Engineering Imperial College London, $\mathrm{SW}_{7} 2 \mathrm{AZ}$, London, UK. \\ 32Department of Bioengineering Imperial College London, SW7 2AZ, London, UK.
}

\begin{abstract}
Bioglass ${ }^{\circledast}$ was the first synthetic biomaterial that formed a chemical bond to bone. Although bioactive glass scaffolds can mimic bone's porous structure, they are brittle. Sol-gel derived hybrids could overcome this problem because their nanoscale co-networks of silica and organic polymer have the potential to provide unique physical properties and controlled homogenous biodegradation. Copolymers of methyl methacrylate (MMA) and 3-(trimethoxysilyl)propyl methacrylate (TMSPMA) has been used as an organic source for hybrids to take advantage of its self-hardening property. However, the effect of well-defined poly(MMA-co-TMSPMA) architecture in the hybrid system has not been investigated. Here, linear, randomly branched and star shaped methacrylate based copolymers were synthesized via reversible addition-fragmentation chain transfer (RAFT) polymerization method. These copolymers were then used to fabricate hybrids. The 3-D polymer structure had a significant effect on mechanical properties, providing higher strain to failure while maintaining a compressive strength similar to sol-gel glass. Star copolymer-SiO ${ }_{2}$ hybrids had a modulus of toughness 9.6 fold greater, and Young's modulus 4.5 fold lower than a sol-gel derived bioactive glass. During in vitro cell culture, $\mathrm{MC}_{3} \mathrm{~T}_{3}$-E1 osteoblast precursor cells adhered on the surface regardless of the polymer structure. Introducing star polymers to inorganic-organic hybrids opens up possibilities for the fine-tuning physical properties of bone scaffold materials.
\end{abstract}

\section{Introduction}

Bioactive glass particles provoke more rapid bone regeneration than other bioceramics ${ }^{1,2,3,4}$. Porous bioactive glass scaffolds can be fabricated with inter-connected pores and compressive strengths that match porous bone ${ }^{5,6,7}$, but they are too brittle for sites that are subjected to cyclic loading, ${ }^{5,8}$. Inorganic-organic hybrids are of great interest because their molecular level interaction between the two components can provide synergistic properties while acting as a single phase material ${ }^{10,11,12,13}$. To do this, covalent bonding is needed between the inorganic and organic molecules, producing a material termed a class II hybrid ${ }^{14}$. A common method is to functionalize the organic component with an organosilane coupling agent, such as glycidoxypropyl trimethoxysilane (GPTMS), prior to introduction of the polymer to the solgel process ${ }^{15}$. Natural polymers, such as poly $(\gamma$-glutamic acid) ${ }^{16,17}$, gelatin ${ }^{15,18}$, and chitosan ${ }^{19,20,21,22,23}$ have been used as an organic source. However, controlling the reactions between nucleophiles on the polymer, e.g. $-\mathrm{COOH}$ groups, and the epoxide ring of the GPTMS is challenging $^{24}$. An ideal polymer for hybrid production would already contain pendant siloxane groups for incorporation into the sol-gel process.

Polymethacrylate can be copolymerized with methyl methacrylate (MMA) and 3-(trimethoxysilyl)propyl meth- acrylate (TMSPMA) to produce an alkoxysilane containing polymer. Hybrids of poly(MMA-co-TMSPMA) with a co-network of $\mathrm{SiO}_{2}$ have been investigated as biomaterials due to promising mechanical properties and bioactivity $25,26,27,28,29,30,31$. However, the studies were more focused on macroscopic properties of the hybrids. The only variable investigated for the organic source was the TMSPMA content within the copolymers. The poly(MMA-co-TMSPMA) were also synthesized with conventional (un-controlled) free-radical polymerization method with high dispersities $(Đ s)$ ranging from 1.77 to 2.35 .

The effect of polymer architecture on drug and gene delivery systems and nanoparticle assembly has been determined, using controlled polymerization ${ }^{32,333,34,35}$. We report here the first study introducing such well-defined polymers, with different 3-D architectures, into organicinorganic class II sol-gel hybrids.

We used RAFT polymerization to synthesize welldefined poly(MMA-co-TMSPMA) structures. Linear, randomly branched, and star architecture copolymers were made and they were introduced in a class II hybrid system via sol-gel. The molecular weight (MW) and TMSPMA molar ratio of the three different copolymers, and inorganic-organic hybrid compositions were kept constant to set the standardized parameters. The aim was to 


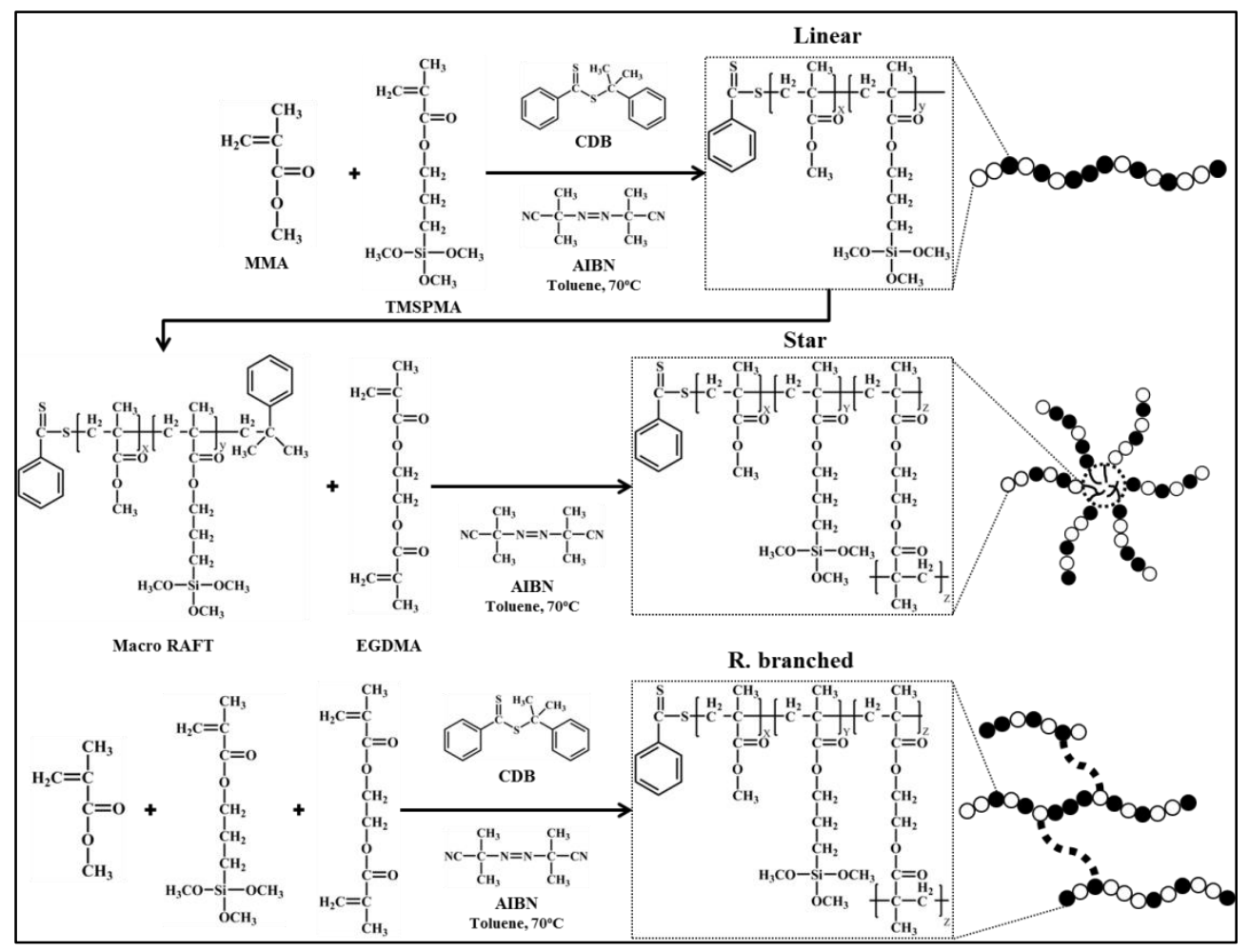

Figure 1: RAFT polymerization of MMA-co-TMSMA copolymers of three different architectures; linear, randomly branched and star. Linear and randomly branched copolymers were synthesized by one-pot RAFT polymerization method. Star copolymer was synthesized by an arm-first approach where the arm, or macro RAFT, was made through same method as the linear copolymer, and the arms were cross-linked with a dimethacrylate branching agent.

determine the effect of polymer architecture on mechanical properties and to determine whether bone cell attachment was affected.

\section{Experimental section}

Materials. Methyl methacrylate (MMA, 99\%), 3(trimethoxysilyl)propyl methacrylate (TMSPMA, 98\%), ethylene glycol dimethacrylate (EGDMA, 98\%), 2-phenyl2-propyl benzodithioate (CDB, RAFT agent, 99\%), 2,2'azobis(2-methylpropionitrile) (AIBN, initiator, 98\%), 2,2diphenyl-1-picrylhydrazyl hydrate $(\mathrm{DPPH}$, free radical inhibitor, 99\%), calcium hydride $\left(\mathrm{CaH}_{2}, 95 \%\right)$, silica gel (6o $\AA$, 70-230 mesh), basic alumina $\left(\mathrm{Al}_{2} \mathrm{O}_{3}, 95 \%\right)$, nhexane $(95 \%)$, toluene (polymerization solvent, 99\%), tetrahydrofuran (THF, analytical and HPLC grade, 99.9\%), deuterated chloroform $\left(\mathrm{CDCl}_{3}, 99.8 \%\right)$, tetraethyl orthosilcate (TEOS, 98\%), and hydrochloric acid solution $(1 \mathrm{M} \mathrm{HCl})$ were purchased from Sigma-Aldrich. Prior to polymerization, MMA and EGDMA were passed through basic alumina columns to remove inhibitors and acidic impurities (TMSPMA was passed through neutral alumina due to its alkoxysilane group hydrolyzing). Then, they were stirred over $\mathrm{CaH}_{2}$ for $\mathrm{i}$ h to neutralize traces of moisture in the presence of DPPH. Finally, all the monomers were vacuum distilled prior to the polymerization. AIBN was recrystallized in ethanol. Toluene was dried in the presence of silica gel, which was heated up to $250^{\circ} \mathrm{C}$ for 4 $\mathrm{h}$ prior to the use. All the glassware were dried overnight at $120^{\circ} \mathrm{C}$ and assembled hot under dynamic vacuum be- fore use. Cell culture reagents were purchased from Invitrogen and Sigma-Aldrich UK unless specified otherwise. MC3T3-E1 preosteoblast cell line (ATCC, UK) was culture expanded in monolayer cultures in basal $\alpha$-MEM supplemented with $10 \%(\mathrm{v} / \mathrm{v})$ FCS (foetal calf serum), 100 unit $/ \mathrm{ml}$ penicillin and $100 \mu \mathrm{g} / \mathrm{ml}$ streptomycin. Cultures were maintained in humidified atmosphere at $37^{\circ} \mathrm{C}, 5 \%$ $\mathrm{CO}_{2}$ and $21 \% \mathrm{O}_{2}$. Cells were passaged upon confluence using $500 \mu \mathrm{g} / \mathrm{ml}$ trypsin-EDTA (ethylene diamine tetraacetic acid).

Linear and randomly branched polymer synthesis. The two polymers were synthesized by one-pot RAFT polymerization method (schematically illustrated in Fig. 1, top and bottom). For the linear polymer synthesis, $\mathrm{MMA}_{480}-\mathrm{Co}-\mathrm{TMSPMA}_{48}$, a schlenk tube was loaded with AIBN (0.04 mmol, 5.00 mg), CDB (0.07 mmol, $0.02 \mathrm{~mL}$ ), MMA (o.07 mol, 7.16 mL), TMSPMA (6.72 mmol, 1.6o mL) and toluene as a solvent. The components of the schlenk tube were subsequently degassed three times by freezevacuum-thaw cycle under argon atmosphere, and were heated in an oil bath to $70^{\circ} \mathrm{C}$ to initiate the polymer synthesis. Then, the copolymer was precipitated in $n$-hexane in order to remove unreacted contents. Randomly branched polymer synthesis was also one-pot RAFT synthesis similar to that of the 'linear polymer' synthesis, apart from introducing EGDMA as the branching agent in the molar ratio of MMA:EGDMA 100:0.7. 
Star polymer synthesis. The star polymer (shown second in Fig. 1) was also synthesized by RAFT by using the "arm-first" approach method. The arm, i.e. the macro RAFT, of the star polymer was of similar composition as the previously synthesised linear polymer but of lower molecular weight ( $\mathrm{MW}=15 \mathrm{~kg} / \mathrm{mol})$. So AIBN (o.13 mmol, $0.02 \mathrm{~g}$ ), CDB (0.25 mmol, $0.06 \mathrm{~mL}$ ), MMA (o.06 mol, 6.50 $\mathrm{mL}$ ) and TMSPMA (6.0o mmol, $1.45 \mathrm{~mL}$ ) were used with toluene as a solvent. After the macro RAFT was synthesized, it was purified by $n$-hexane precipitation. Then the macro RAFT was re-dissolved in dry toluene and AIBN and the EGDMA cross-linker were added in a schlenk tube. The molar ratios used were Macro RAFT:EGDMA:AIBN 8:1:0.3. The contents were degassed three times by freeze-vacuum-thaw cycle under argon atmosphere, and were heated in an oil bath to $70^{\circ} \mathrm{C}$. The polymerization was kept for $24 \mathrm{~h}$. Then, the polymer was precipitated in $n$-hexane and ethanol. The precipitation was repeated 3 times in order for the unreacted arm to be removed.

Hybrid synthesis. After the copolymers were purified, toluene was removed using a rotary evaporator under vacuum pressure. Then, the polymers were dissolved in THF (pot 1). In pot 2, inorganic source was prepared by hydrolysing TEOS with the molar ratio of TEOS:water: $\mathrm{HCl}$ of 1:3.7:0.o1. The amount of TEOS added such that the overall wt $\%$ of the hybrid would be $70 \mathrm{wt} \%$ organic and $30 \mathrm{wt} \%$ inorganic. The mixture was vigorously stirred for 40 minutes, and full hydrolysis was visually confirmed (from cloudy to clear). When TEOS was fully hydrolysed, pot 1 was poured into pot 2 and the mixture was stirred for $1 \mathrm{~h}$ at room temperature. The mixture was poured into a Teflon mold and then placed in $40^{\circ} \mathrm{C}$ oven to gel/age for 3 weeks. The mold was then opened to dry in a $60^{\circ} \mathrm{C}$ oven for 10 days. The procedure is schematically illustrated in Fig. 2. Four hybrid monolith samples of each composition were synthesized with dimension of height $10.26 \pm 1.23 \mathrm{~mm}$, and diameter $8.63 \pm 0.57 \mathrm{~mm}$.

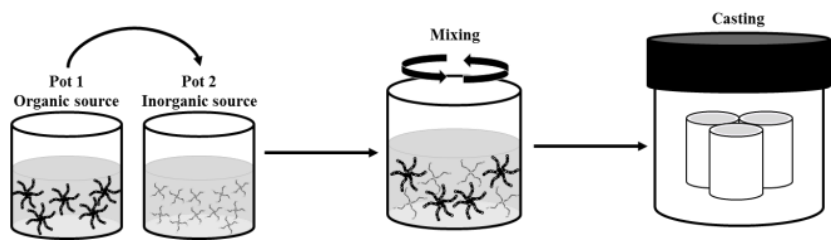

Figure 2: Organic-inorganic class II hybrid synthesis.

Polymer characterization. The conversion rate of monomers to polymer and polymer composition were determined using proton Nuclear Magnetic Resonance ('H-NMR) spectroscopy. This was performed in deuterated $\mathrm{CDCl}_{3}$ using a $400-\mathrm{MHz}$ Avance Bruker NMR spectrometer. For the \% conversion calculations, trioxane was loaded to the schlenk tube prior to the polymerization and was used as an internal standard to determine the \% conversion of the monomer to the polymer. Specifically, trioxane peak at $5.1 \mathrm{ppm}$ was compared to the unreacted monomer peak at $5.5 \mathrm{ppm}$ to confirm the conversion rate. The polymer composition of the final copolymers was calculated using the MMA methoxy group and the
TMSPMA methylene group next to the $\mathrm{Si}$ (discussed in detail in the Results \& Discussion).

The average MWs and $\oslash$ s for all the polymers and their precursors were determined by Gel Permeation Chromatography (GPC). An Agilent, SECurity GPC system, with a Polymer Standard Service (PSS) SDV analytical linear M column (SDAo83005LIM) was used. All the polymers were dissolved in THF and were filtered through $0.45 \mu \mathrm{m}$ polytetrafuloroethylene (PTFE) syringe filters. The GPC eluent was THF, which was pumped with a flow rate of $1 \mathrm{ml} / \mathrm{min}$ by a '126o Iso' isocratic pump. An Agilent 1260 RID detector was used to measure the refractive index signal. The calibration curve was based on PMMA standards with MWs of 2, 4, 8, 20, 50, $100 \mathrm{kgmol}^{-1}$.

Hybrid characterization. The functional groups of the hybrids and copolymers were analysed by Fourier Transform Infrared spectroscopy (FTIR, Nicolet iSio, Thermo Scientific) with an attenuated total reflectance module. 32 scans were averaged to yield $4 \mathrm{~cm}^{-1}$ resolution.

The mechanical properties of the hybrids were investigated by uniaxial compression test. Compression testing was performed using Zwick 1474 instrument with a $100 \mathrm{kN}$ load cell at a consistent speed of $0.1 \mathrm{~mm} /$ minute. Modulus of toughness $\left(U_{T}\right)$ was calculated by measuring area underneath the stress-strain compression curve.

Thermogravimetry (TGA) analysis was used to measure the organic/inorganic \% weight of the hybrid samples. TGA was performed with Netzsch sta 449c in air. The hybrid samples were placed in a platinum crucible and heated to $800^{\circ} \mathrm{C}$ at $10^{\circ} \mathrm{C} / \mathrm{min}$.

Cytotoxicity test. Potential in vitro cytotoxicity effects of the hybrid material on $\mathrm{MC}_{3} \mathrm{~T}_{3}$-E1 cells were assessed in accordance to ISO $10993^{-5^{36}}$ and ISO 10993-1237. Dissolution products released by the samples $(0.2 \mathrm{~g} / \mathrm{ml}$ in $\alpha$-MEM at $37^{\circ} \mathrm{C}$ ) over a $72 \mathrm{~h}$ period were prepared. Medical grade polyethylene (PE) was used as negative control (non-cytotoxic) and polyurethane (PU) containing $0.1 \%$ $(\mathrm{w} / \mathrm{w})$ zinc diethyldithiocarbamate (ZDEC) was used as positive control (reproducible cytotoxic response). The dissolution products were filter sterilized and dilution series $(25 \%, 50 \%, 75 \%$ and $100 \%)$ were prepared and supplemented with $10 \%(\mathrm{v} / \mathrm{v})$ FCS prior to use in cell viability assays.

Cell viability was assessed by a calorimetric cell metabolic activity assay based on the conversion of 3-(4,5dimethylthiazol-2-yl)-2,5-diphenyltetrazolium bromide (MTT) into formazan. MC 3 T3-E1 cells were seeded on 96well plates at $1 \times 10^{4}$ cells per well and left to grow in basal $\alpha$-MEM for $24 \mathrm{~h}$ until a sub-confluent monolayer was formed. The culture media was removed and, $\mathrm{MC}_{3} \mathrm{~T}_{3}-\mathrm{E}_{1}$ cells were then incubated with fresh basal $\alpha$-MEM, the dissolution products of hybrid material or controls (100 $\mu \mathrm{l} /$ well) for further $24 \mathrm{~h}$. The culture media was removed and then MTT diluted in serum-free $\alpha$-MEM at a concentration of $1 \mathrm{mg} / \mathrm{ml}$ was added $(50 \mu \mathrm{l} /$ well). Following an incubation period of $2 \mathrm{~h}$, the MTT solution was removed and each well was filled with $100 \mu$ isopropanol and shaken briefly to dissolve the formazan derivatives. The 


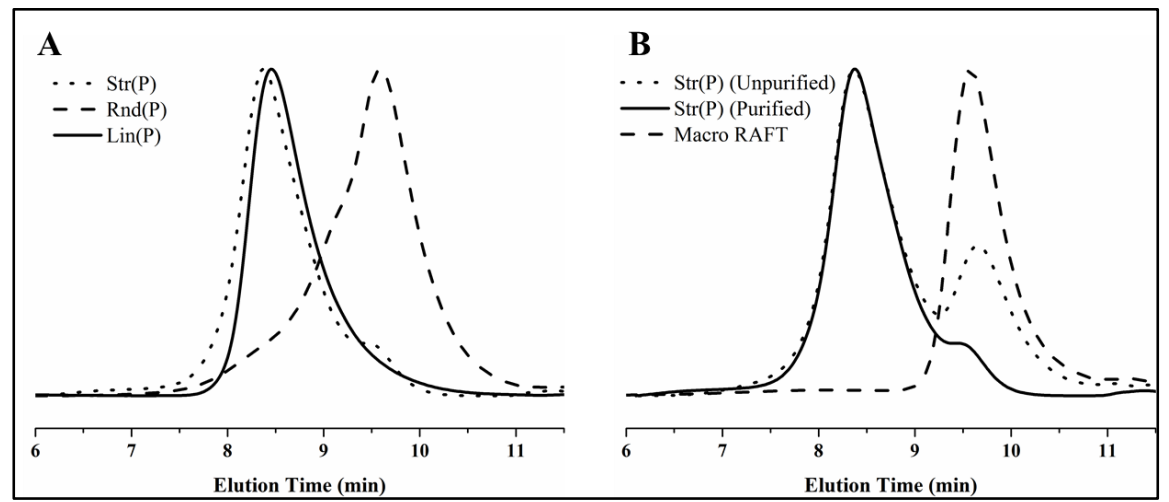

Figure 4: A) GPC traces of the Lin( $(\mathrm{P})$, Rnd(P), and $\operatorname{Str}(\mathrm{P})$, and $\mathrm{B}) \mathrm{GPC}$ traces of the $\operatorname{Str}(\mathrm{P})$ and the Macro RAFT (corresponding precursor, or arm of the $\operatorname{Str}(\mathrm{P}))$.

optical density was measured spectrophotometrically at $570 \mathrm{~nm}$ using a microplate reader (SpectraMax M5).

Cell culture on hybrid materials. For cell attachment studies, hybrid disks $(5 \times 5 \times 1$ (h) $\mathrm{mm})$ were manufactured and sterilised with $70 \%$ ethanol for 1 minute. Following washing with PBS, each sample was placed in serum-free $\alpha$-MEM for 30 minutes prior to cell seeding.

Monolayer expanded $\mathrm{MC}_{3} \mathrm{~T}_{3}-\mathrm{E}_{1}$ cells were harvested and suspended in basal $\alpha$-MEM at a concentration $1 \times 10^{6}$ cells $/ \mathrm{ml}$. $10 \mu \mathrm{l}$ of cell suspension was seeded onto each hybrid disk and, incubated in humidified atmosphere at $37^{\circ} \mathrm{C}, 5 \% \mathrm{CO}_{2}$ and $21 \% \mathrm{O}_{2}$ for $2 \mathrm{~h}$. Each cell seeded disk was then submerged in fresh basal $\alpha$-MEM and cultured for further $72 \mathrm{~h}$.

Immunohistochemistry staining. Cell-seeded disks were fixed with $4 \%(\mathrm{w} / \mathrm{v})$ paraformaldehyde (PFA) and used for immunohistochemical analysis of cell attachment. Following permeabilisation with buffered $0.5 \%$ (c/v) Triton X-100 in PBS (300 mM sucrose, $50 \mathrm{mM} \mathrm{NaCl}$, $3 \mathrm{mM} \mathrm{MgCl} 2,20 \mathrm{mM}$ Hepes and $\mathrm{pH}$ 7.2) and blocking with $10 \mathrm{mg} / \mathrm{ml} \mathrm{BSA}$ in PBS, samples were incubated with anti-Vimentin antisera (1:500 dilution in $10 \mathrm{mg} / \mathrm{ml} \mathrm{BSA} \mathrm{in}$ PBS, rabbit polyclonal, IgG, Abcam, Cambridge, UK) at $4{ }^{\circ} \mathrm{C}$ for $1 \mathrm{~h}$. This was followed by hour-long incubation with Alexa Fluor ${ }^{\circ}$ 488-conjugated secondary antibody. Negative controls (omission of the primary antisera) were performed in all immunohistochemistry procedures. No staining was observed in the samples used as negative controls.

F-actin was labelled using CytoPainter F-actin staining kit (Abcam, Cambridge, UK) following the manufacturer's instruction. Briefly, Alexa Fluor ${ }^{\circ}$ 568-conjugated phalloidin (1:100o dilution in labelling buffer) was added simultaneously with the secondary antibody during the incubation period. All samples were counter-stained with DAPI $(0.1 \mu \mathrm{g} / \mathrm{ml}$ in PBS).

Confocal microscopy. The samples were imaged under confocal microscopy (Leica $\mathrm{SP}_{5} \mathrm{MP}$ laser scanning confocal microscope and software, Leica Microsystems, Wetzlar, Germany).

\section{Results \& Discussion}

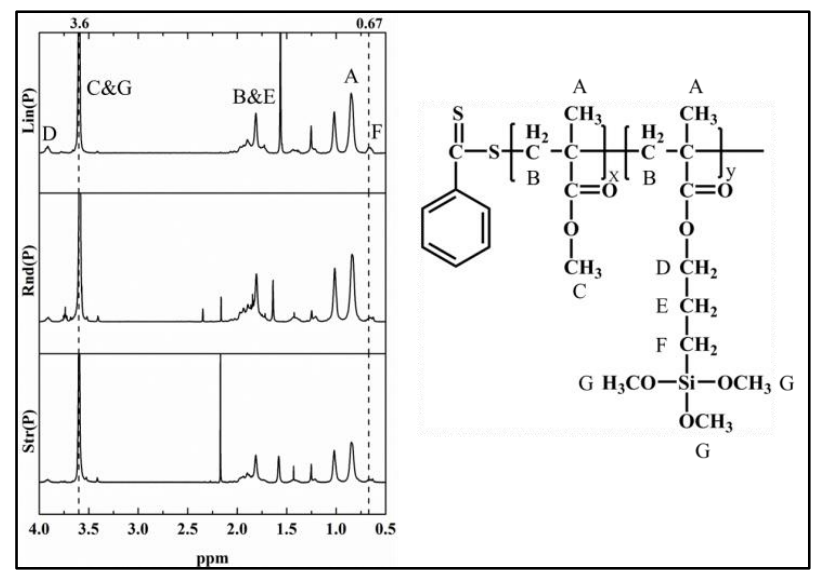

Figure 3: ${ }^{1} \mathrm{H}-\mathrm{NMR}$ spectra of linear, randomly branched, and star PMMA copolymers in $\mathrm{CDCl}_{3}$

Polymer Characterization. PMMA copolymers; MMA-co-TMSPMA (linear), MMA-co-TMSPMA-coEGDMA (randomly branched) and MMA-co-TMSPMAstar, were successfully synthesized with the targeted molar ratio. They will be refer to as $\operatorname{Lin}(\mathrm{P})$, $\mathrm{Rnd}(\mathrm{P})$, and $\mathrm{Str}(\mathrm{P})$ respectively. ${ }^{1} \mathrm{H}-\mathrm{NMR}$ analysis was used to characterize the structure of the copolymers (Fig. 3). The comparison of the peaks at $3.6 \mathrm{ppm}$ (methoxy group, $\mathrm{C} \& \mathrm{G}$ ) and $0.67 \mathrm{ppm}\left(\mathrm{Si}-\mathrm{CH}_{2}-, \mathrm{F}\right)$ confirmed that the molar ratio were close to our targeted value ( $9 \mathrm{~mol} \%$ of TMSPMA).

In Table 1, the MWs and the Đs of all the synthesized copolymers are shown. The aim was for all copolymers to have similar MWs, but this is not possible for the Rnd(P) because the polymer architecture is not well-defined or controlled, so the $\oslash$ was broad $(\fallingdotseq=2.27)$. The $M_{n}$ s of the $\operatorname{Lin}(\mathrm{P})$ and $\operatorname{Str}(\mathrm{P})$ copolymers were very similar $(\sim 60$ $\mathrm{kg} / \mathrm{mol}$ ) and both had satisfactorily narrow Đs, which were similar to the previously published studies (Đs ranging from 1.22 to 1.49$)^{38,39,40}$.

GPC traces of the three purified copolymers are shown in Fig. 4A. The GPC traces of the star polymer's before and after purification are shown in Fig. 4B. Fig. 4B shows that before purification, a star polymer was obtained (at 


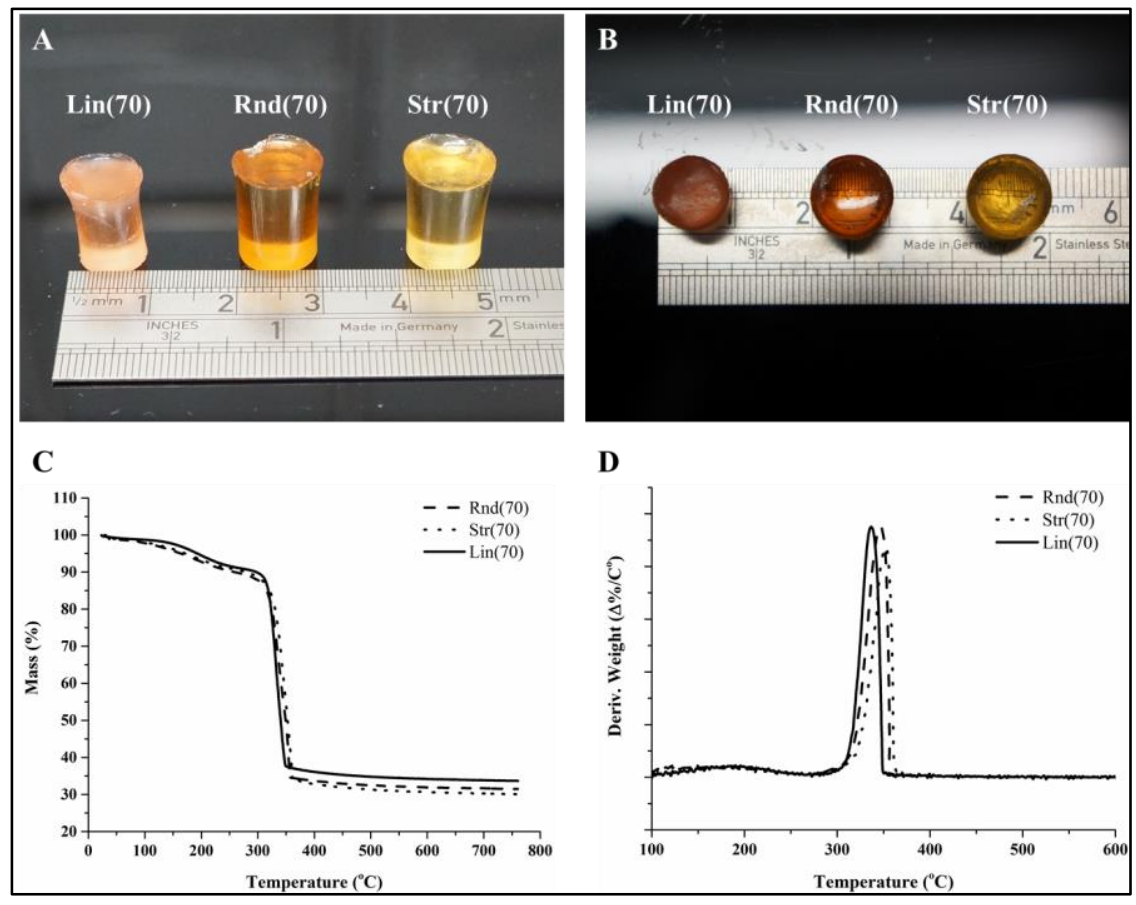

Figure 6: A) and B) Photos of the class II hybrid monoliths (Lin(70),Rnd(70) and $\operatorname{Str}(70)$ from left to right) C) Thermogravimetry (TGA) and D) differential thermal gravimetry (DTG) curve of the hybrids.

Table 1 Molecular weights and dispersities of the copolymers with different architectures

\begin{tabular}{cccc}
\hline & $\begin{array}{c}M_{n^{\mathrm{a}}} \\
(\mathbf{k g} / \mathbf{m o l})\end{array}$ & $\begin{array}{c}\boldsymbol{M}_{w^{\mathrm{a}}} \\
(\mathbf{k g} / \mathbf{m o l})\end{array}$ & $\Xi^{\mathrm{a}}$ \\
\hline $\operatorname{Lin}(\mathbf{P})$ & 59.5 & 66.8 & 1.12 \\
$\operatorname{Rnd}(\mathbf{P})$ & 11.8 & 27.0 & 2.27 \\
Macro RAFT & 12.5 & 13.4 & 1.07 \\
$\operatorname{Str}(\mathbf{P})$ & 61.4 & 74.1 & 1.21 \\
\hline
\end{tabular}

aDetermined using GPC with an RI detector, which was calibrated with PMMA standards.

lower elution time) while some linear macro RAFT was still present, not having yet inter-linked to produce a star polymer. This was expected for the "arm-first" approach to produce star polymers ${ }^{41,42,43,44,45}$. The "unreacted" arm, macro RAFT, was removed by the sequential precipitations, but some could still be seen in the GPC traces for $\operatorname{Str}(\mathrm{P})$ (Purified). After the purification, the main $\operatorname{Str}(\mathrm{P})$ refractive index intensity was $97 \%$ compared to the unreacted arms, which is a value considered as a well-defined star polymer architecture.

Hybrid Characterization. Hybrids synthesized with the different polymer architectures of $\operatorname{Lin}(\mathrm{P})$, Rnd(P), and $\operatorname{Str}(\mathrm{P})$ will be referred to as $\operatorname{Lin}(70)$, Rnd(70), and $\operatorname{Str}(70)$ respectively. Molecular structure of the three different hybrids and copolymers were confirmed by FTIR analysis (Fig. 5). Vibration bands expected in methacrylate based copolymer were shown in all three copolymer spectra; C$\mathrm{H}$ vibration $\left(2950,1485 \mathrm{~cm}^{-1}\right)$ from the methacrylate backbone, $\mathrm{C}=\mathrm{O}$ stretching $\left(1725 \mathrm{~cm}^{-1}\right) \quad \mathrm{C}-\mathrm{C}-\mathrm{O}$ asymmetric stretching $\left(1239 \mathrm{~cm}^{-1}\right)$ and C-O-C symmetric stretching $\left(1140 \mathrm{~cm}^{-1}\right)$ of the ester group from the methacrylate moieties, and $\mathrm{Si}-\mathrm{O}-\mathrm{CH}_{3}$ and $\mathrm{Si}-\mathrm{C}$ of the alkoxysilane group from TMSPMA. Upon hybrid synthesis, stronger absorption bands characteristic of the condensed silica network arose, such as $\mathrm{Si}-\mathrm{O}-\mathrm{Si}$ asymmetric stretching with $\mathrm{Si}-\mathrm{OH}$ stretching while possessing the polymer absorption bands. FTIR spectra showed that the copolymers and silica network were both present in the hybrid system. Fig. 6A, B shows that crack free inorganic-organic class II hybrid

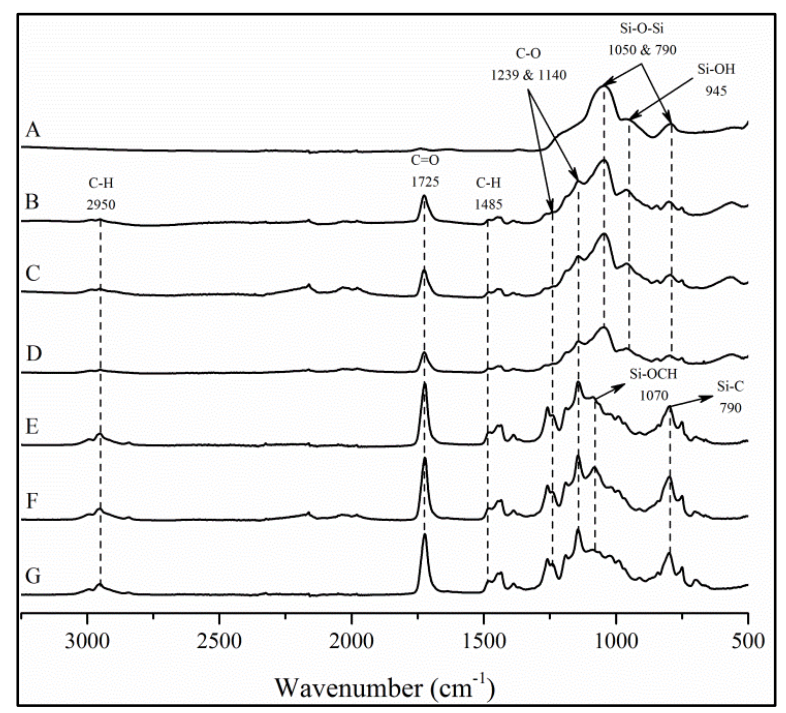

Figure 5: FTIR spectra of a) silica glass hybrids b) $\operatorname{Str}(70)$, c) $\operatorname{Rnd}(70)$, d) Lin(7o); and polymerse) Str(P), f) Rnd(P), and g) $\operatorname{Lin}(\mathrm{P})$. 
Table 2. Mechanical properties of the class II hybrids. 7oS3oC glass* values are adapted from Poologasundarampillai et $\mathrm{al}^{17}$. Standard deviations are derived from the average values.

\begin{tabular}{|c|c|c|c|c|c|c|}
\hline & $\begin{array}{c}\text { Yield Stress } \\
\text { MPa }\end{array}$ & $\begin{array}{c}\text { Yield Strain } \\
\%\end{array}$ & $\begin{array}{c}E \\
\text { GPa }\end{array}$ & $\begin{array}{c}\text { Ultimate Stress } \\
\text { MPa }\end{array}$ & $\begin{array}{c}\text { Strain at Failure } \\
\%\end{array}$ & $\begin{array}{r}U_{T} \\
\text { GPa }\end{array}$ \\
\hline${ }_{70 S_{3}} C^{*}$ & - & - & 2.71 & 88.3 & 4.13 & 0.13 \\
\hline $\operatorname{Lin}(70)$ & $41 \pm 1$ & $4.3 \pm 0.3$ & $1.1 \pm 0.1$ & $75 \pm 21$ & $21 \pm 7$ & 0.92 \\
\hline $\operatorname{Rnd}(70)$ & $51 \pm 8$ & $6.1 \pm 1.5$ & $1.0 \pm 0.1$ & $85 \pm 11$ & $23 \pm 4$ & 0.89 \\
\hline $\operatorname{Str}(70)$ & $26 \pm 3$ & $4.8 \pm 1.0$ & $0.6 \pm 0.2$ & $69 \pm 8$ & $28 \pm 0.5$ & 1.25 \\
\hline
\end{tabular}

cylinders were fabricated. All the hybrid samples had yellowish color due to the degradation of the RAFT agent. The hybrid samples were transparent from the front view (Fig. 6A). However, Lin(70) was translucent from the top view, which could be due to the surface roughness of the Teflon mold that was used (Fig. 6B). The class II hybrids were made with inorganic-organic ratio of 30-70 wt\%, because we were not able to fabricate tall crack free monolith samples with higher inorganic content. This is likely be due to higher capillary stresses within the silica nanopores during the drying stage, at higher silica contents $^{13}$. Thermal analysis was conducted to confirm the final inorganic-organic ratio (Fig. 6C, D).

All DTG traces of the hybrids showed thermal decomposition of the organic component starting at $\approx 340^{\circ} \mathrm{C}$ $\left(337^{\circ} \mathrm{C}, 347^{\circ} \mathrm{C}\right.$, and $35^{\circ} \mathrm{C}$ : $\operatorname{Lin}(70)$, Rnd $(70)$, and $\operatorname{Str}(70)$ respectively (Fig. 6C). After the decomposition, the TGA curve flattened because only the inorganic component was left behind. Final weight remaining was $31 \pm 1.8 \%$, which was close to our targeted inorganic composition of $30 \mathrm{wt} \%$. There were no distinctive peaks present, other than trivial degradation attributed to the evaporation of water and trace of other solvents, during thermal decomposition in lower temperature $\left(<300^{\circ} \mathrm{C}\right)$ as shown in Fig. $6 \mathrm{D}$, which represent weak linkages of PMMA ${ }^{46}$. The decomposition temperature was similar to that of poly(MMA-co-TMSPMA) ${ }^{47}$, and previous PMMA hybrids $^{28}$.

Uniaxial compression test was performed on the tall cylindrical monolith samples (height/diameter $>1$ ), following ISO 640:2003 standard ${ }^{17}$. The hybrid mechanical properties were also compared to $70 \mathrm{OS}_{30 \mathrm{C}}$ bioactive glass ( $70 \mathrm{~mol} \% \mathrm{SiO}_{2}, 30 \mathrm{~mol} \% \mathrm{CaO}$ ) monolith sample that was included in a previous study ${ }^{17}$. Fig. 7 shows representative stress/strain curves that demonstrate that the hybrids were remarkably less brittle than $70 \mathrm{~S}_{30} \mathrm{C}$. The hybrids first displayed an elastic deformation to yield stress, and then a plastic deformation was followed until the failure. In the plastic deformation region, self-hardening was observed, which can be seen in neat PMMA compression test ${ }^{4}{ }^{8}$. The bulk mechanical properties of the hybrid samples are compared in Table 2. Ultimate compressive stress for all three different hybrids was high, in the range of $70-$ $80 \mathrm{MPa}$, and similar to the value of $70 \mathrm{~S}_{30 \mathrm{C}}$ glass. However, the hybrids were more flexible and tougher. $\operatorname{Str}(70)$ had 4.3 fold lower compressive modulus $(E)$ and 6.9 fold

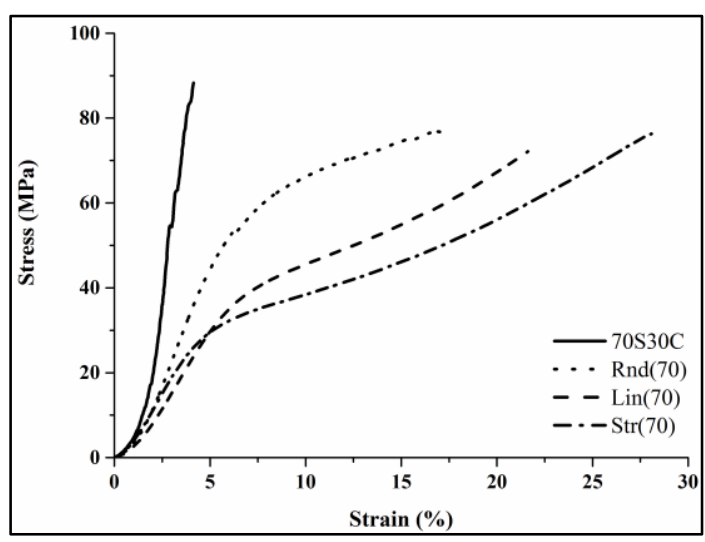

Figure 7: Representative uniaxial compression test curve of the hybrid monoliths and $70 \mathrm{OS}_{30 \mathrm{C}}$ bioactive glass.

higher strain at failure than that of the $7 \mathrm{OS}_{30} \mathrm{C}$, in addition modulus to toughness $\left(U_{T}\right)$, energy required to rupture a material, was increased by 9.6 fold. Mode of failure of the hybrids tended towards that of the organic component as organic content increased, agreeing with previous studies on hybrids ${ }^{49,50}$. The hybrids fabricated in this study had $70 \mathrm{wt} \%$ organic polymer, which could be the explanation of displaying such polymeric and selfhardening behavior.

Polymer architecture had also affected mechanical properties of the hybrids. The most noticeable change was seen in yield stress and Young's modulus values. Yield stress of $\operatorname{Str}(70)$ was nearly half that of $\operatorname{Rnd}(70)$, and reduced by 1.6 fold compare to $\operatorname{Lin}(70)$. Also, compressive modulus of the $\operatorname{Str}(70)$ decreased by approximately 1.6 fold compared to the other two hybrids. However, $\operatorname{Str}(70)$ had the highest $U_{T}$ and strain to failure, which can be interpreted to mean it is a more flexible and tougher material. Flexibilty and toughness could be related to the elastic cross-linked core (based on EGDMA). The star copolymer synthesized in this study resembles star gels, a silica network forming precursor that has an organic core surrounded by alkoxysilane group terminating arms ${ }^{51,52,53}$, which also showed more flexibility than the conventional sol-gel glasses.

These interesting differences in mechanical properties could be due to the hydrodynamic radius of each architectures. From the result, it is hypothesized that the star architecture offers high flexibility, or strain value, due 


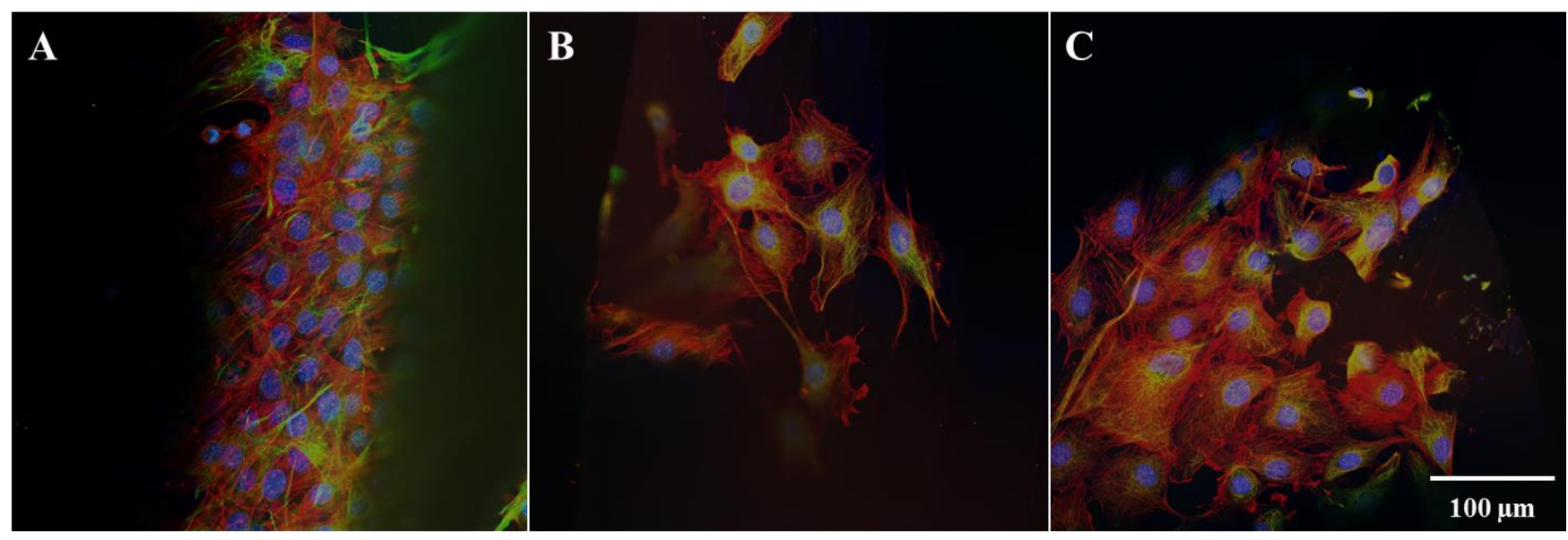

Figure 9: Immunohistochemical staining of the cytoskeleton of $\mathrm{MC}_{3} \mathrm{~T}_{3}$ cells cultured on the A) Lin(70), B) Rnd(7o), and C) $\operatorname{Str}(70)$ surfaces after $72 \mathrm{~h}$ of culture. Representative images were stacks of Vimentin immunostain (green), F-actin labelling (red) and DAPI nuclear counter stain (blue) produced via confocal microscopy.

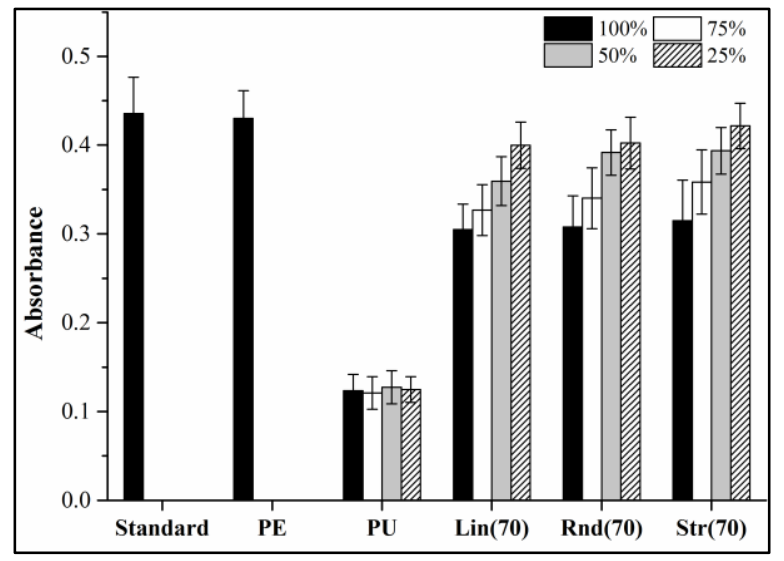

Figure 8: Assessment of cell viability by MTT metabolic activity assay following ISO 10993 standards 37 . The viability of

$\mathrm{MC}_{3} \mathrm{~T}_{3}$ cells cultured in dissolution products of Lin (70), Rnd (70) and Str (70) hybrids was 70.9\%, 71.5\% and 73.2\% respectively to that of standard culture media and negative control (PE). Dilution of the dissolution products improved cell viability to the level comparable to both non-cytotoxic controls.

to the elastic cross-linking core despite it having compact radius. For complicated randomly branched architecture, when compared with linear polymers, the structure can be viewed as different lengths of linear polymers that arebranched together in an uncontrolled manner. Also, this structure can be understood as shorter MW linear polymer chains bound together randomly, which could produce more compact spatial radius and lead to a brittle hybrid system. Although, flexible EGDMA branching was used for the randomly branched architecture, the trimethoxysilyl groups from TMSPMA was not positioned as the star architecture which could also result such brittle hybrids.

An ideal biomaterial for bone repair should promote osteogenic cell attachment. ${ }^{54}$. Therefore, cytotoxicity level and the ability of hybrids to support cell attachment are key factors to consider for biological applications. In the present study, the MTT assay was performed in accordance to ISO $10993^{37}$ (Biological evaluation of medical devices). The ISO standards state that if viability is reduced to $<70 \%$ of blank (i.e. non-cytotoxic controls) the test material will be considered to have a cytotoxic potential and the $50 \%$ dilution of the test sample should have at least the same or a higher viability than the $100 \%$ extract for the test to be deemed valid. Fig. 8 shows all three hybrids can be considered biocompatible and thus be manufactured for future in vivo studies.

Cell attachment on the three hybrid materials was examined by immunohistochemistry and confocal microscopy following 72 h of cell culture. As shown in Fig. 9, the expression of the 2 major cytoskeletal constituents vimentin (green), intermediate filament proteins, and Factin(red), microfilaments, was evident in $\mathrm{MC}_{3} \mathrm{~T}_{3}$ cells regardless of the hybrids differentiated by the polymer architecture. The optimum cell attachment is generally known to achieved in the intermediate surface wettability values ${ }^{54}$. Although PMMA containing polymers are known to be hydrophobic in nature, they were shown to swell by absorbing small amount of water 55 .

\section{Conclusion}

Poly(MMA-co-TMSPMA)-SiO ${ }_{2}$ class II hybrids with three different architectures were synthesized by a sol-gel route. The polymer architectures, especially the star shape, had influence on the mechanical properties of the hybrid system. The star polymer with the elastic crosslinking core was more flexible and had a high modulus of toughness. Additionally, all the hybrids passed the ISO standards for cytotoxicity test, and osteoblast precursor cells were able to adhere on the hybrids. This was a first study to introduce an organic source synthesized by controlled living polymerization and well-defined polymer architectures to inorganic-organic class II hybrids. Higher tailorability in the physical properties can be achieved by designing different polymer architectures for the hybrid system. 


\section{AUTHOR INFORMATION}

\section{Corresponding Author}

*Department of Materials, Imperial College London, UK julian.r.jones@imperial.ac.uk.

\section{Author Contributions}

The manuscript was written through contributions of all authors. All authors have given approval to the final version of the manuscript.

\section{Funding Sources}

EPSRC (EP/Mo19950/1).

\section{ACKNOWLEDGMENT}

The authors would like to acknowledge Imperial College Rector's Scholarship Fund and EPSRC (EP/Mo19950/1) for funding JJC and part of this project. Raw data can be obtained on request from julian.r.jones@imperial.ac.uk.

\section{ABBREVIATIONS}

MMA, Methyl methacrylate; TMSPMA, 3(trimethoxysilyl)propyl methacrylate; EGDMA, Ethylene glycol dimethacrylate; CDB, 2-phenyl-2-propyl benzodithioate; RAFT, reversible addition-fragmentation chain transfer; MW, Molecular weight; ${ }^{1} \mathrm{H}-\mathrm{NMR}$, proton Nuclear Magnetic Resonance; $Đ$, Dispersity; GPC, Gel Permeation Chromatography; FTIR, Fourier Transform Infrared spectroscopy; TGA, Thermogravimetry; $\mathrm{U}_{T}$, modulus to toughness; MTT, 3-(4,5dimethylthiazol-2-yl)-2,5-diphenyltetrazolium bromide;

\section{REFERENCES}

1. Oonishi, H.; Hench, L. L.; Wilson, J.; Sugihara, F.; Tsuji, E.; Kushitani, S.; Iwaki, H., Comparative bone growth behavior in granules of bioceramic materials of various sizes. Journal of Biomedical Materials Research 1999, 44, 31-43.

2. Oonishi, H.; Hench, L. L.; Wilson, J.; Sugihara, F.; Tsuji, E.; Matsuura, M.; Kin, S.; Yamamoto, T.; Mizokawa, S., Quantitative comparison of bone growth behavior in granules of Bioglass (R), A-W glass-ceramic, and hydroxyapatite. Journal of Biomedical Materials Research 200o, 51, 37-46.

3. Oonishi, H.; Kushitani, S.; Yasukawa, E.; Iwaki, H.; Hench, L. L.; Wilson, J.; Tsuji, E. I.; Sugihara, T., Particulate bioglass compared with hydroxyapatite as a bone graft substitute. Clinical Orthopaedics and Related Research 1997, 316325 .

4. Wheeler, D. L.; Eschbach, E. J.; Hoellrich, R. G.; Montfort, M. J.; Chamberland, D. L., Assessment of resorbable bioactive material for grafting of critical-size cancellous defects. $J$ Orthop Res 2000, 18, 140-148.

5. Jones, J. R.; Ehrenfried, L. M.; Hench, L. L., Optimising bioactive glass scaffolds for bone tissue engineering. Biomaterials 2006, 27, 964-973.

6. Fu, Q.; Saiz, E.; Tomsia, A. P., Direct ink writing of highly porous and strong glass scaffolds for load-bearing bone defects repair and regeneration. Acta Biomaterialia 2011, 7, 35473554 .

7. Doiphode, N. D.; Huang, T. S.; Leu, M. C.; Rahaman, M. N.; Day, D. E., Freeze extrusion fabrication of 13-93 bioactive glass scaffolds for bone repair. Journal of Materials ScienceMaterials in Medicine 2011, 22, 515-523.

8. Fu, Q. A.; Saiz, E.; Tomsia, A. P., Bioinspired Strong and Highly Porous Glass Scaffolds. Advanced Functional Materials 2011, 21, 1058-1063.
9. Wu, Z. Y.; Hill, R. G.; Yue, S.; Nightingale, D.; Lee, P. D.; Jones, J. R., Melt-derived bioactive glass scaffolds produced by a gel-cast foaming technique. Acta Biomater 2011, 7, 1807-1816. 10. Sanchez, C.; Julian, B.; Belleville, P.; Popall, M., Applications of hybrid organic-inorganic nanocomposites. Journal of Materials Chemistry 2005, 15, 3559-3592.

11. Mammeri, F.; Le Bourhis, E.; Rozes, L.; Sanchez, C., Mechanical properties of hybrid organic-inorganic materials. Journal of Materials Chemistry 2005, 15, 3787-3811.

12. Nicole, L.; Boissiere, C.; Grosso, D.; Quach, A.; Sanchez, C., Mesostructured hybrid organic-inorganic thin films. Journal of Materials Chemistry 2005, 15, 3598-3627.

13. Jones, J. R., Review of bioactive glass: From Hench to hybrids. Acta Biomaterialia 2013, 9, 4457-4486.

14. Novak, B. M., Hybrid Nanocomposite Materials between Inorganic Glasses and Organic Polymers. Advanced Materials 1993, 5, 422-433.

15. Mahony, O.; Tsigkou, O.; Ionescu, C.; Minelli, C.; Ling, L.; Hanly, R.; Smith, M. E.; Stevens, M. M.; Jones, J. R., SilicaGelatin Hybrids with Tailorable Degradation and Mechanical Properties for Tissue Regeneration. Advanced Functional Materials 2010, 20, 3835-3845.

16. Poologasundarampillai, G.; Yu, B.; Tsigkou, O.; Valliant, E.; Yue, S.; Lee, P. D.; Hamilton, R. W.; Stevens, M. M.; Kasuga, T.; Jones, J. R., Bioactive silica-poly(gamma-glutamic acid) hybrids for bone regeneration: effect of covalent coupling on dissolution and mechanical properties and fabrication of porous scaffolds. Soft Matter 2012, 8, 4822-4832.

17. Poologasundarampillai, G.; Yu, B. B.; Tsigkou, O.; Wang, D. M.; Romer, F.; Bhakhri, V.; Giuliani, F.; Stevens, M. M.; McPhail, D. S.; Smith, M. E.; Hanna, J. V.; Jones, J. R., Poly(gamma-glutamic acid)/Silica Hybrids with Calcium Incorporated in the Silica Network by Use of a Calcium Alkoxide Precursor. Chemistry-a European Journal 2014, 20, 8149-816o.

18. Mahony, O.; Yue, S.; Turdean-Ionescu, C.; Hanna, J. V.; Smith, M. E.; Lee, P. D.; Jones, J. R., Silica-gelatin hybrids for tissue regeneration: inter-relationships between the process variables. Journal of Sol-Gel Science and Technology 2014, 69, 288-298.

19. Connell, L. S.; Romer, F.; Suarez, M.; Valliant, E. M.; Zhang, Z. Y.; Lee, P. D.; Smith, M. E.; Hanna, J. V.; Jones, J. R., Chemical characterisation and fabrication of chitosan-silica hybrid scaffolds with 3-glycidoxypropyl trimethoxysilane. Journal of Materials Chemistry B 2014, 2, 668-68o.

20. Shirosaki, Y.; Tsuru, K.; Hayakawa, S.; Osaka, A.; Lopes, M. A.; Santos, J. D.; Costa, M. A.; Fernandes, M. H., Physical, chemical and in vitro biological profile of chitosan hybrid membrane as a function of organosiloxane concentration. Acta Biomaterialia 2009, 5, 346-355.

21. Shirosaki, Y.; Tsuru, K.; Hayakawa, S.; Osaka, A.; Lopes, M. A.; Santos, J. D.; Fernandes, M. H., In vitro cytocompatibility of MG63 cells on chitosan-organosiloxane hybrid membranes. Biomaterials 2005, 26, 485-493.

22. Tsuru, K.; Shirosaki, Y.; Hayakawa, S.; Osaka, A.; Lopes, M. A.; Santos, J. D.; Fernandes, M. H., In vitro biodegradability of chitosan-organosiloxane hybrid membrane. Bioceramics, Vol 17 2005, 284-286, 823-826.

23. Wang, D. M.; Romer, F.; Connell, L.; Walter, C.; Saiz, E.; Yue, S.; Lee, P. D.; McPhail, D. S.; Hanna, J. V.; Jones, J. R., Highly flexible silica/chitosan hybrid scaffolds with oriented pores for tissue regeneration. Journal of Materials Chemistry $B$ 2015, 3, 756o-7576.

24. Gabrielli, L.; Connell, L.; Russo, L.; Jimenez-Barbero, J.; Nicotra, F.; Cipolla, L.; Jones, J. R., Exploring GPTMS reactivity against simple nucleophiles: chemistry beyond hybrid materials fabrication. Rsc Advances 2014, 4, 1841-1848. 
25. Rhee, S. H.; Choi, J. Y., Preparation of a bioactive poly(methyl methacrylate)/silica nanocomposite. Journal of the American Ceramic Society 2002, 85, 1318-1320.

26. Rhee, S. H.; Hwang, M. H.; Si, H. J.; Choi, J. Y., Biological activities of osteoblasts on poly(methyl methacrylate)/silica hybrid containing calcium salt. Biomaterials 2003, 24, 901-906.

27. Lee, K. H.; Rhee, S. H., The mechanical properties and bioactivity of poly(methyl methacrylate)/SiOz-CaO nanocomposite. Biomaterials 2009, 30, 3444-3449.

28. Ravarian, R.; Wei, H.; Rawal, A.; Hook, J.; Chrzanowski, W.; Dehghani, F., Molecular interactions in coupled PMMA-bioglass hybrid networks. Journal of Materials Chemistry B 2013, 1, 1835-1845.

29. Ravarian, R.; Zhong, X.; Barbeck, M.; Ghanaati, S.; Kirkpatrick, C. J.; Murphy, C. M.; Schindeler, A.; Chrzanowski, W.; Dehghani, F., Nanoscale Chemical Interaction Enhances the Physical Properties of Bioglass Composites. Acs Nano 2013, 7 , 8469-8483.

3o. Macon, A. L. B.; Page, S. J.; Chung, J. J.; Amdursky, N.; Stevens, M. M.; Weaver, J. V. M.; Hanna, J. V.; Jones, J. R., A structural and physical study of sol-gel methacrylate-silica hybrids: intermolecular spacing dictates the mechanical properties. Physical Chemistry Chemical Physics 2015, 17, 2912429133.

31. Maçon, A. L. B.; Li, S.; Chung, J. J.; Nommeots-Nomm, A.; Solanki, A.; Stevens, M. M.; Jones, J. R., Ductile silica/methacrylate hybrids for bone regeneration. Journal of Materials Chemistry B 2016.

32. Listak, J.; Hakem, I. F.; Ryu, H. J.; Rangou, S.; Politakos, N.; Misichronis, K.; Avgeropoulos, A.; Bockstaller, M. R., Effect of Chain Architecture on the Compatibility of Block Copolymer/Nanoparticle Blends. Macromolecules 2009, 42, 5766-5773.

33. Nandan, B.; Lee, C. H.; Chen, H. L.; Chen, W. C., Molecular architecture effect on the microphase separations in supramolecular comb-coil complexes of polystyrene-blockpoly(2-vinylpyridine) with dodecylbenzenesulfonic acid: $(\mathrm{AB})(\mathrm{n}) \mathrm{A}(\mathrm{n})$ block-arm star copolymer. Macromolecules 2005, 38, 10117-10126.

34. Georgiou, T. K., Star polymers for gene delivery. Polymer International 2014, 63, 1130-1133.

35. Boyer, C.; Bulmus, V.; Davis, T. P.; Ladmiral, V.; Liu, J. Q.; Perrier, S., Bioapplications of RAFT Polymerization. Chemical Reviews 2009, 109, 5402-5436.

36. ISO 10993-5, Biological evaluation of medical devices. In Part 5: Tests for in vitro cytotoxicity, 2009.

37. ISO 10993-12, Biological evaluation of medical devices. In Part 12: Sample preparation and reference materials, 2012.

38. Guo, S. Z.; Zhang, C.; Wang, W. Z.; Liu, T. X., Preparation and characterization of organic-inorganic hybrid nanomaterials using polyurethane-b-poly[3-(trimethoxysilyl) propyl methacrylate] via RAFT polymerization. Express Polymer Letters 2010, 4, 17-25.

39. Peng, B.; Liu, Y.; Shi, Y.; Li, Z. B.; Chen, Y. M., Thermoresponsive organic-inorganic hybrid vesicles with tunable membrane permeability. Soft Matter 2012, 8, 12002-12008.

40. Chang, C.; Wei, H.; Feng, J.; Wang, Z. C.; Wu, X. J.; Wu, D. Q.; Cheng, S. X.; Zhang, X. Z.; Zhuo, R. X., Temperature and $\mathrm{pH}$ Double Responsive Hybrid Cross-Linked Micelles Based on P(NIPAAm-co-MPMA)-b-P(DEA): RAFT Synthesis and
"Schizophrenic" Micellization. Macromolecules 20o9, 42, 48384844 .

41. Blencowe, A.; Tan, J. F.; Goh, T. K.; Qiao, G. G., Core cross-linked star polymers via controlled radical polymerisation. Polymer 2009, 50, 5-32.

42. Georgiou, T. K.; Phylactou, L. A.; Patrickios, C. S., Synthesis, characterization, and evaluation as transfection reagents of ampholytic star copolymers: Effect of star architecture. Biomacromolecules 2006, 7, 3505-3512.

43. Themistou, E.; Patrickios, C. S., Synthesis and characterization of star polymers and cross-linked star polymer model networks containing a novel, silicon-based, hydrolyzable cross-linker. Macromolecules 2004, 37, 6734-6743.

44. Themistou, E.; Patrickios, C. S., Star polymers and polymer networks containing a novel, hydrolyzable diacetalbased dimethacrylate cross-linker: Synthesis, characterization, and hydrolysis kinetics. Macromolecules 2007, 40, 5231-5234.

45. Themistou, E.; Patrickios, C. S., Synthesis and characterization of amphiphilic star copolymers of 2(dimethylamino) ethyl methacrylate and methyl methacrylate: Effects of architecture and composition. European Polymer Journal 2007, 43, 84-92.

46. Kashiwagi, T.; Inaba, A.; Brown, J. E.; Hatada, K.; Kitayama, T.; Masuda, E., Effects of Weak Linkages on the Thermal and Oxidative-Degradation of Poly(Methyl Methacrylates). Macromolecules 1986, 19, 216o-2168.

47. Wei, Y.; Yang, D. C.; Bakthavatchalam, R., ThermalStability and Hardness of New Polyacrylate-Sioz Hybrid Sol-Gel Materials. Materials Letters 1992, 13, 261-266.

48. Chen, L.; Zhai, D.; Huan, Z. G.; Ma, N.; Zhu, H. B.; Wu, C. T.; Chang, J., Silicate bioceramic/PMMA composite bone cement with distinctive physicochemical and bioactive properties. Rsc Advances 2015, 5, 37314-37322.

49. Mammeri, F.; Le Bourhis, E.; Rozes, L.; Sanchez, C., Elaboration and mechanical characterization of nanocomposites thin films - Part I: Determination of the mechanical properties of thin films prepared by in situ polymerisation of tetraethoxysilane in poly(methyl methacrylate). Journal of the European Ceramic Society 2006, 26, 259-266.

50. Mammeri, F.; Rozes, L.; Le Bourhis, E.; Sanchez, C. Elaboration and mechanical characterization of nanocomposites thin films - Part II. Correlation between structure and mechanical properties of $\mathrm{SiO}_{2}$-PMMA hybrid materials. Journal of the European Ceramic Society 2006, 26, 267-272.

51. Sharp, K. G.; Michalczyk, M. J., Star gels: New hybrid network materials from polyfunctional single component precursors. Journal of Sol-Gel Science and Technology 1997, 8, 541-546.

52. Sharp, K. G., Inorganic/organic hybrid materials. Advanced Materials 1998, 10, 1243-1248.

53. Manzano, M.; Arcos, D.; Delgado, M. R.; Ruiz, E.; Gil, F. J.; Vallet-Regi, M., Bioactive star gels. Chemistry of Materials 2006, 18, 5696-5703.

54. Bacakova, L.; Filova, E.; Rypacek, F.; Svorcik, V.; Stary, V., Cell adhesion on artificial materials for tissue engineering. Physiological Research 2004, 53, S35-S45.

55. N'Diaye, M.; Pascaretti-Grizon, F.; Massin, P.; Basle, M. F.; Chappard, D., Water Absorption of Poly(methyl methacrylate) Measured by Vertical Interference Microscopy. Langmuir 2012, 28, 11609-11614. 
Authors are required to submit a graphic entry for the Table of Contents (TOC) that, in conjunction with the manuscript title, should give the reader a representative idea of one of the following: A key structure, reaction, equation, concept, or theorem, etc., that is discussed in the manuscript. Consult the journal's Instructions for Authors for TOC graphic specifications.

Insert Table of Contents artwork here

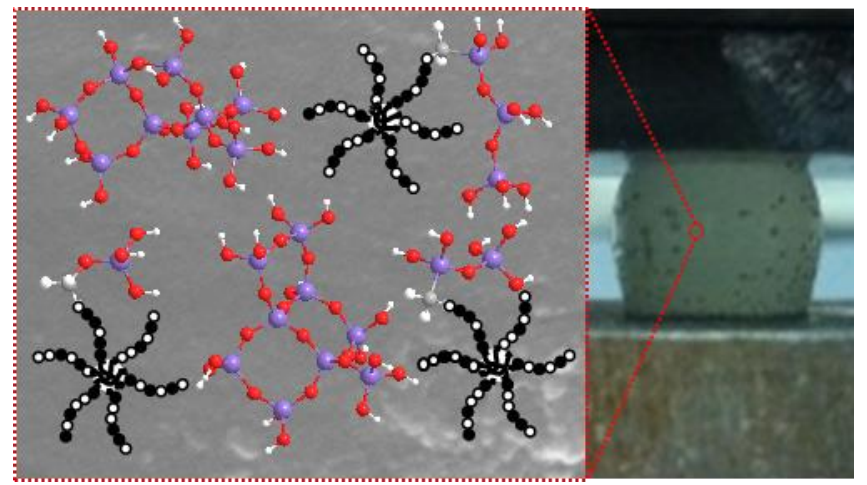

